\title{
DETERMINATION OF THE MOST FAVORABLE SHAPES FOR THE CYLINDRICAL CONCAVE ELECTROSTATIC QUADRUPOLE LENS
}

\author{
Oday A. Hussein \\ Department of Physics, College of Science, Al-Nahrain University, Baghdad-Iraq. \\ E-mail: udayalobaidy@yahoo.com
}

\begin{abstract}
The optimum design of electrostatic quadrupole lens of cylindrical concave electrodes is computed with the aid of transfer matrices method, where the axial field distribution and the optical properties are determined.

The trajectory equation of motion in Cartesian coordinates is solved and the path of charged particles beam traversing the axial field is determined. Then the beam trajectory along the lens axis is used to calculate the optical properties of the lens.

The optimization calculations are made to find the optimum optical properties and the design of an electrode shape of lens. The calculation procedure include determination both of electrode shape parameter and excitation, then the aberration parameters in both horizontal and vertical planes along the optical axis are computed.

Both spherical and chromatic aberration coefficients are reduced via changing the geometrical shapes of electrodes by taking the different gap angles of electrode into account. The results show that the choice of the limited value of the gap angle gives us the optimum optical properties and the best values of the aberration coefficients.
\end{abstract}

\section{Introduction}

One of the simplest quadrupole lenses with cylindrical concave electrodes consist of four identical parts are symmetrical cut out from the cylinder .The remaining four parts represent the form a concave cylindrical quadrupole lens.

The field distribution in electrostatic quadrupole lens depends on a large number of parameters : electrode voltage ratios, aperture size, electrode thicknesses and spacing between them, as well as the radial and longitudinal dimensions of the electrode. The particular electrode configuration may result in a single value of $K$ [1].

An ideal quadrupole field is accurately realized by hyperbolic electrodes. However, this may be approximated by cylindrical concave electrodes with a proper electrode angle consisting of four concave cylindrical electrodes and as is shown in Fig. (1). In this figure $\gamma$ and $\Gamma$ are half of the electrode angle and half of the gap angle respectively. In the concave cylindrical electrodes the length $\mathrm{L}$ is the "effective length" which has been found experimentally to be given by [2] :

$$
\mathrm{L}=\mathrm{I}+0.451 \mathrm{a}
$$

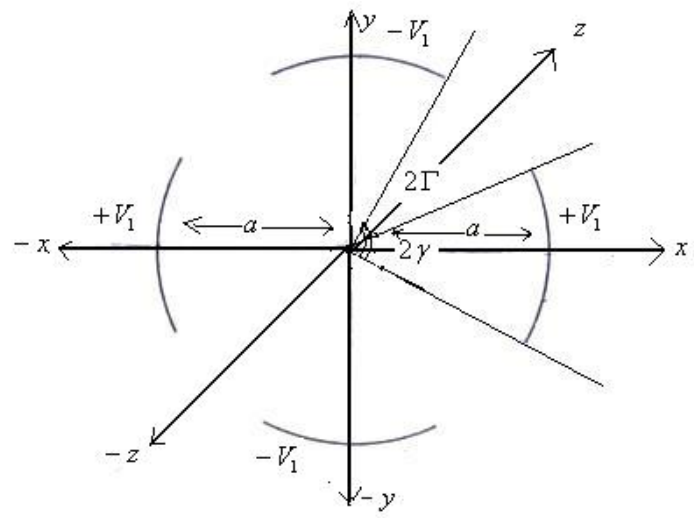

Fig.(1) : Quadrupole lens of cylindrical concave electrodes [2].

The coefficient of the quadrupole field component $\mathrm{K}$ for cylindrical concave electrodes is described as [3] and [4]:

$$
\mathrm{K}=(4 / \pi) \sin (2 \Gamma)
$$

\section{Quadrupole Field Distribution in Cylindrical Concave Electrodes}

The potential distribution of a quadrupole lens with cylindrical electrodes is calculated by solution of Laplace equation in three dimensions. The results show that the modified bell-shaped is a very closed 
approximation to the potential function for the relatively long quadrupole lens $\ell \gg \mathrm{a}$. The solution of Laplaces equation in cylindrical coordinates is $V(r, \theta, z)$ is expressed as [3]:

$$
\mathrm{V}(\mathrm{r}, \theta, \mathrm{z})=\mathrm{D}(\mathrm{z}) \mathrm{V}_{1}(\mathrm{r} / \mathrm{a})^{2} \cos (2 \theta)
$$

where

$$
\mathrm{D}(\mathrm{z})=\mathrm{K} \mathrm{f}(\mathrm{z})
$$

where $V_{1}$ is the potential of the electrode, and the form of the $f(z)$ function is normalized to unity (at the center $z=0$ ).

The potential distribution for electrostatic quadrupole lens of cylindrical concave electrodes depends on many parameters, such as aperture radius $a$ which is equal to electrode radius $\mathrm{R} \quad(\mathrm{a}=3 \mathrm{~mm}$ in the present calculations), geometrical length I $(\mid=10 \mathrm{~mm}$ in the present calculations $)$, effective length $\mathrm{L}$ is given in equation (1), and electrode gap between the electrodes $2 \Gamma$ (see Fig. (1)).

Fig.(2) shows the axial potential distribution ratio $\left(\mathrm{V}(\mathrm{r}, \theta, \mathrm{z}) / \mathrm{V}_{1}\right)$ which is computed by using equation (3). From the figure the shape of the axial potential distribution is a very closed to the modified bell-shaped. This result agrees with the results mentioned in various references, [2], [3], and [5].

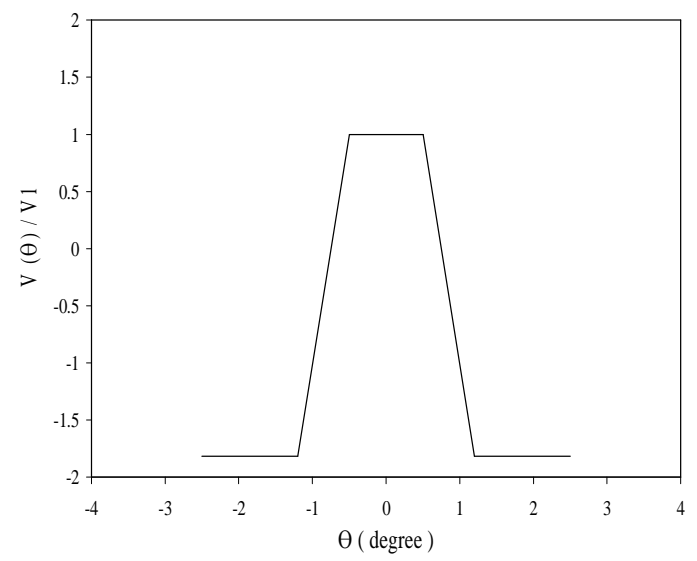

Fig.(2) : The potential distribution ratio of electrostatic quadrupole lens of cylindrical concave electrodes.

\section{The Trajectory of Electron Beam}

The trajectory equations in Cartesian coordinates for the charged-particles beam traversing the field of a quadrupole lens are given by [6]:

$$
\begin{aligned}
& x^{\prime \prime}+\beta^{2} f(z) x=0 \\
& y^{\prime \prime}-\beta^{2} f(z) y=0
\end{aligned}
$$

where $\beta^{2}$ is the lens excitation and is given by:

$$
\beta^{2}=V_{1} K / a^{2} V_{0}
$$

where $\mathrm{V}_{1}$ is the electrode voltage, $\mathrm{V}_{0}$ acceleration voltage, $\mathrm{x}^{\prime \prime}$ and $\mathrm{y}^{\prime \prime}$ are the second derivatives with respect to $\mathrm{z}$, and $\mathrm{K}$ is a coefficient accounting for the shape of electrodes. [7] and [8].

The general solution of the second-order linear homogeneous differential equations (5) and (6) can always be written in the following matrix form, respectively.

$$
\begin{aligned}
& \left(\begin{array}{c}
\mathrm{x}(\mathrm{z}) \\
\mathrm{x}^{\prime}(\mathrm{z})
\end{array}\right)=\mathrm{T}_{\mathrm{x}}\left(\begin{array}{c}
\mathrm{x}_{0}(\mathrm{z}) \\
\mathrm{x}_{0}^{\prime}(\mathrm{z})
\end{array}\right) . . \\
& \left(\begin{array}{c}
\mathrm{y}(\mathrm{z}) \\
\mathrm{y}^{\prime}(\mathrm{z})
\end{array}\right)=\mathrm{T}_{\mathrm{y}}\left(\begin{array}{c}
\mathrm{y}_{0}(\mathrm{z}) \\
\mathrm{y}_{0}^{\prime}(\mathrm{z})
\end{array}\right) .
\end{aligned}
$$

where $\mathrm{x}_{\mathrm{o}}$ and $y_{o}$ are the initial displacements from the optical axis in the $\mathrm{x}-\mathrm{z}$ and $\mathrm{y}-\mathrm{z}$ plane respectively, and $x_{0}^{\prime}$ and $y_{0}^{\prime}$ are the initial gradients of the beam in the corresponding planes. And the parameters $\mathrm{T}_{\mathrm{x}}$ and $\mathrm{T}_{\mathrm{y}}$ are the transfer matrices in the convergence plane and the divergence plane, respectively which are given by [1] and [9]: 


$$
\mathrm{T}_{\mathrm{x}}=\left(\begin{array}{cc}
\frac{\mathrm{d} \cos \left(\mathrm{W}_{\mathrm{x}} \psi\right)}{\sin (\psi)} & \frac{\mathrm{d} \sin \left(\mathrm{W}_{\mathrm{x}} \psi\right)}{\sin (\psi)} \\
\frac{\mathrm{d}_{\mathrm{x}} \sin (\psi) \sin \left(\mathrm{W}_{\mathrm{x}} \psi\right)+\mathrm{d} \cos (\psi) \cos \left(\mathrm{W}_{\mathrm{x}} \psi\right)}{\sin ^{2}(\psi)\left[1+\left(\mathrm{z}-\mathrm{z}_{\mathrm{L}} / \mathrm{d}\right)^{2}\right] \mathrm{d}} & \frac{\mathrm{d} \cos (\psi) \sin \left(\mathrm{W}_{\mathrm{x}} \psi\right)-\mathrm{d}_{\mathrm{x}} \sin (\psi) \cos \left(\mathrm{W}_{\mathrm{x}} \psi\right)}{\sin ^{2}(\psi)\left[1+\left(\mathrm{z}-\mathrm{z}_{\mathrm{L}} / \mathrm{d}\right)^{2}\right] \mathrm{d}}
\end{array}\right)
$$

$$
\mathrm{T}_{\mathrm{y}}=\left(\begin{array}{cc}
\frac{\mathrm{d} \cos \left(\mathrm{W}_{\mathrm{y}} \psi\right)}{\sin (\psi)} & \frac{\mathrm{d} \sin \left(\mathrm{W}_{\mathrm{y}} \psi\right)}{\sin (\psi)} \\
\frac{\mathrm{d} \mathrm{Wy} \sin (\psi) \sin \left(\mathrm{W}_{\mathrm{y}} \psi\right)+\mathrm{d} \cos (\psi) \cos (\mathrm{Wy} \psi)}{\sin ^{2}(\psi)\left[1+\left(\mathrm{z}-\mathrm{z}_{\mathrm{L}} / \mathrm{d}\right)^{2}\right] \mathrm{d}} & \frac{\mathrm{d} \cos (\psi) \sin \left(\mathrm{W}_{\mathrm{y}} \psi\right)-\mathrm{dW}_{\mathrm{y}} \sin (\psi) \cos \left(\mathrm{W}_{\mathrm{y}} \psi\right)}{\sin ^{2}(\psi)\left[1+\left(\mathrm{z}-\mathrm{z}_{\mathrm{L}} / \mathrm{d}\right)^{2}\right] \mathrm{d}}
\end{array}\right)
$$

where:

$$
\begin{aligned}
& W_{x}=1-\beta^{2} d^{2} \text { (convergence plane) } \\
& W_{y}=1+\beta^{2} d^{2} \text { (divergence plane) }
\end{aligned}
$$

and

$$
\left(\mathrm{z}-\mathrm{z}_{\mathrm{L}}\right) / \mathrm{d}=\cot (\psi)
$$

Figs. (3) and (4) show the trajectory of charged particles beam through quadrupole lens of cylindrical concave electrodes lying in both converging plane and diverging plan, respectively. It should be made clear that a quadrupole lens can defocus the beam in its convergence plane after crossing the optical axis but it can never be a focusing device in its divergence plane since the beam is deflected away from the optical axis.

The trajectories are plotted for the following initial conditions:

$$
\mathrm{x}_{\mathrm{o}}=1 \text { and } \mathrm{x}_{\mathrm{o}}^{\prime}=0 ; \mathrm{y}_{\mathrm{o}}=1 \text { and } \mathrm{y}_{\mathrm{o}}^{\prime}=0 \text {. }
$$

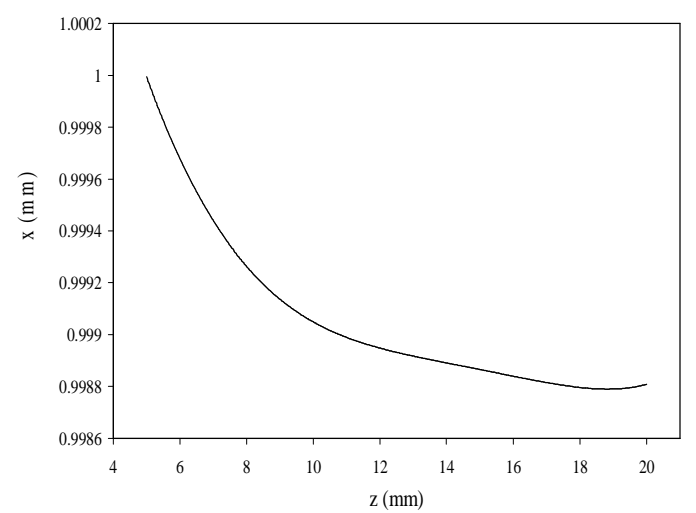

Fig. (3) : Trajectory of charge particles beam

in the electrostatic quadrupole lens of cylindrical concave electrodes for convergence plane.

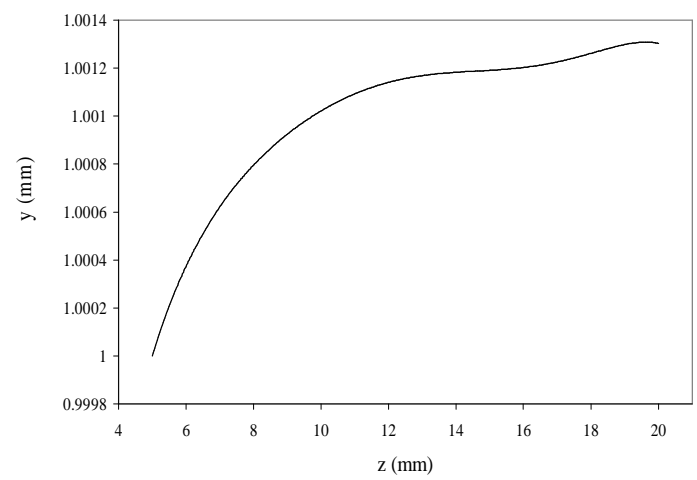

Fig. (4): Trajectory of charge particles beam in the electrostatic quadrupole lens of cylindrical concave electrodes for divergence plane.

Spherical Aberration of a Quadrupole Lens

In a quadrupole lens, the spherical aberration in the Gaussian image plane can be expressed as [10]:

$$
\begin{aligned}
& \Delta x(z i)=\left(C_{30} \alpha^{3}+C_{12} \alpha \gamma^{2}\right) \\
& \Delta y(z i)=\left(D_{21} \alpha^{2} \gamma+D_{03} \gamma^{3}\right)
\end{aligned}
$$

where $\alpha$ and $\gamma$ are the image side semiaperture angles in the $\mathrm{x}-\mathrm{z}$ and $\mathrm{y}-\mathrm{z}$ plane respectively, The coefficients $\mathrm{C}$ characterize the aberration in the convergence plane, and $\mathrm{D}$ in the divergence plane The coefficient $C_{30}$ determines the aberration of the real width image in the plane $\mathrm{y}=0$, while $\mathrm{D}_{03}$ determines the aberration of the imaginary image in the plane of $\mathrm{x}=0$. And the value of $\psi_{0}$ corresponds to the position of the object and $\psi_{1}$ to that of the image [11].

The spherical aberration coefficients $\mathrm{C}$ and $\mathrm{D}$ are determined from the relations given in [7]: 


$$
\begin{aligned}
\frac{\mathrm{C}_{30}}{\mathrm{~d}}= & \frac{1}{32 \sin ^{4} \psi_{0}}\left[\left(\mathrm{w}_{\mathrm{x}}^{2}-1\right)\left(\mathrm{w}_{\mathrm{x}}^{2}+3\right) \frac{\pi}{\mathrm{w}_{\mathrm{x}}^{5}}+\frac{2\left(7-\mathrm{w}_{\mathrm{x}}^{2}\right)}{4 \mathrm{w}_{\mathrm{x}}^{2}-1}\left(\sin 2 \psi_{0}-\sin 2 \psi_{1}\right)+\left(2-2 \mathrm{n}+3 \mathrm{n}^{2}\right)\right. \\
& \left.\left(\mathrm{w}_{\mathrm{x}}^{2}-1\right)\left[\left(\mathrm{w}_{\mathrm{x}}^{2}-1\right) \frac{\pi}{\mathrm{w}_{\mathrm{x}}^{5}}-\frac{2}{4 \mathrm{w}_{\mathrm{x}}^{2}-1}\left(\sin 2 \psi_{0}-\sin 2 \psi_{1}\right)\right]\right]
\end{aligned}
$$

$$
\begin{aligned}
\frac{\mathrm{C}_{12}}{\mathrm{~d}}= & \frac{1}{32 \mathrm{w}_{\mathrm{y}}^{2} \sin ^{4}\left(\psi_{0}\right)}\left[\left[-4\left[\left(1-\cos \left(2 \pi \frac{\mathrm{w}_{\mathrm{y}}}{\mathrm{w}_{\mathrm{x}}}\right)\right) \sin (2 \psi)_{1}+\mathrm{w}_{\mathrm{y}}\left(1-\cos \left(2 \psi_{1}\right) \sin \left(2 \pi \frac{\mathrm{w}_{\mathrm{y}}}{\mathrm{w}_{\mathrm{x}}}\right)\right]\right.\right.\right. \\
& +3\left(\mathrm{w}_{\mathrm{x}}^{2}-1\right)\left[-2\left(\mathrm{w}_{\mathrm{x}}^{2}-1\right) \frac{\pi}{\mathrm{w}_{\mathrm{x}}^{3}}+\frac{1}{\mathrm{w}_{\mathrm{x}}^{2}-1}\left[-\frac{\mathrm{w}_{\mathrm{y}}^{2}\left(\mathrm{w}_{\mathrm{x}}^{2} \mathrm{w}_{\mathrm{y}}^{2}+2\right)}{4 \mathrm{w}_{\mathrm{x}}^{2} \mathrm{w}_{\mathrm{y}}^{2}-1} \sin \left(2 \psi_{0}\right)+\left(\mathrm{w}_{\mathrm{y}}^{2}+3\right)\right.\right.
\end{aligned}
$$$$
\left.\sin \left(2 \psi_{1}\right)+\frac{3 \mathrm{w}_{\mathrm{y}}^{2}+1}{2 \mathrm{w}_{\mathrm{y}}} \sin \left(2 \mathrm{k} \pi \frac{\mathrm{w}_{\mathrm{y}}}{\mathrm{w}_{\mathrm{x}}}\right)\right]-\frac{3}{4 \mathrm{w}_{\mathrm{x}}^{2} \mathrm{w}_{\mathrm{y}}^{2}-1}\left[\left(4 \mathrm{w}_{\mathrm{y}}^{2}-1\right) \sin \left(2 \psi_{1}\right) \cos \left(2 \pi \frac{\mathrm{w}_{\mathrm{y}}}{\mathrm{w}_{\mathrm{x}}}\right)\right.
$$$$
\left.\left.+\mathrm{w}_{\mathrm{y}}\left(2 \mathrm{w}_{\mathrm{y}}^{2}+1\right) \cos \left(2 \psi_{1}\right) \sin \left(2 \pi \frac{\mathrm{w}_{\mathrm{y}}}{\mathrm{w}_{\mathrm{x}}}\right)\right]\right]+\left(2+2 \mathrm{n}-\mathrm{n}^{2}\right)\left(\mathrm{w}_{\mathrm{x}}^{2}-1\right)\left[2\left(\mathrm{w}_{\mathrm{x}}^{2}-1\right) \frac{\pi}{\mathrm{w}_{\mathrm{x}}^{3}}-\right.
$$$$
\frac{4 \mathrm{w}_{\mathrm{y}}^{2}\left(\mathrm{w}_{\mathrm{x}}^{2}-1\right)}{4 \mathrm{w}_{\mathrm{x}}^{2} \mathrm{w}_{\mathrm{y}}^{2}-1} \sin \left(2 \psi_{0}\right)+\sin \left(2 \psi_{1}\right)-\frac{1}{2 \mathrm{w}_{\mathrm{y}}} \sin \left(2 \pi \frac{\mathrm{w}_{\mathrm{y}}}{\mathrm{w}_{\mathrm{x}}}\right)-\frac{1}{4 \mathrm{w}_{\mathrm{x}}^{2} \mathrm{w}_{\mathrm{y}}^{2}-1}\left[\left(4 \mathrm{w}_{\mathrm{y}}^{2}-1\right)\right.
$$$$
\left.\left.\left.\left.\sin \left(2 \psi_{1}\right) \cos \left(2 \pi \frac{\mathrm{w}_{\mathrm{y}}}{\mathrm{w}_{\mathrm{x}}}\right)+\mathrm{w}_{\mathrm{y}}\left(2 \mathrm{w}_{\mathrm{y}}^{2}+1\right) \cos \left(2 \psi_{1}\right) \sin \left(2 \pi \frac{\mathrm{w}_{\mathrm{y}}}{\mathrm{w}_{\mathrm{x}}}\right)\right]\right]\right]\right]
$$

$$
\begin{aligned}
& \frac{\mathrm{D}_{03}}{\mathrm{~d}}=\frac{\mathrm{w}_{\mathrm{x}}^{2}-1}{32 \mathrm{w}_{\mathrm{y}}^{4} \sin ^{4}\left(\psi_{0}\right)}\left[-\frac{1}{3}\left[2(2+\mathrm{n}) \mathrm{w}_{\mathrm{y}}\left(1-\cos \left(2 \psi_{1}\right)\right)\left(1-\cos \left(2 \pi \frac{\mathrm{w}_{\mathrm{y}}}{\mathrm{w}_{\mathrm{x}}}\right)\right) \sin \left(2 \pi \frac{\mathrm{w}_{\mathrm{y}}}{\mathrm{w}_{\mathrm{x}}}\right)\right.\right. \\
& \left.+(4-\mathrm{n})\left(\cos \left(4 \pi \frac{\mathrm{w}_{\mathrm{y}}}{\mathrm{w}_{\mathrm{x}}}\right)-4 \cos \left(2 \pi \frac{\mathrm{w}_{\mathrm{y}}}{\mathrm{w}_{\mathrm{x}}}\right)+3\right) \sin 2 \psi_{1}\right]-\left(\mathrm{w}_{\mathrm{y}}^{2}+3\right) \frac{\pi}{\mathrm{w}_{\mathrm{x}}}+ \\
& \frac{2 \mathrm{w}_{\mathrm{y}}^{4}\left(5+\mathrm{w}_{\mathrm{x}}^{2}\right)}{\left(\mathrm{w}_{\mathrm{x}}^{2}-1\right)\left(4 \mathrm{w}_{\mathrm{y}}^{2}-1\right)} \sin \left(2 \psi_{0}\right)+\frac{1+\mathrm{w}_{\mathrm{x}}^{2}}{2} \sin \left(2 \psi_{1}\right)+\frac{2}{\mathrm{w}_{\mathrm{y}}} \sin \left(2 \pi \frac{\mathrm{w}_{\mathrm{y}}}{\mathrm{w}_{\mathrm{x}}}\right)-\frac{\mathrm{w}_{\mathrm{x}}^{2}-1}{4 \mathrm{w}_{\mathrm{y}}} \\
& \sin \left(4 \pi \frac{\mathrm{w}_{\mathrm{y}}}{\mathrm{w}_{\mathrm{x}}}\right)-\frac{2}{\mathrm{w}_{\mathrm{x}}^{2}-1}\left[\left(\mathrm{w}_{\mathrm{y}}^{2}+1\right) \sin \left(2 \psi_{1}\right) \cos \left(2 \pi \frac{\mathrm{w}_{\mathrm{y}}}{\mathrm{w}_{\mathrm{x}}}\right)+2 \mathrm{w}_{\mathrm{y}}\left(\cos 2 \psi_{1}\right)\right. \\
& \left.\sin \left(2 \pi \frac{\mathrm{w}_{\mathrm{y}}}{\mathrm{w}_{\mathrm{x}}}\right)\right]-\frac{1}{2\left(4 \mathrm{w}_{\mathrm{y}}^{2}-1\right)}\left[\left(5 \mathrm{w}_{\mathrm{y}}^{2}+1\right) \sin \left(2 \psi_{1}\right) \cos \left(4 \pi \frac{\mathrm{w}_{\mathrm{y}}}{\mathrm{w}_{\mathrm{x}}}\right)+2 \mathrm{w}_{\mathrm{y}}\left(\mathrm{w}_{\mathrm{y}}^{2}+2\right)\right. \\
& \left.\cos \left(2 \psi_{1}\right) \sin \left(4 \pi \frac{\mathrm{w}_{\mathrm{y}}}{\mathrm{w}_{\mathrm{x}}}\right)\right]+\frac{1}{3}\left(2-2 \mathrm{n}+3 \mathrm{n}^{2}\right)\left(\mathrm{w}_{\mathrm{x}}^{2}-1\right)\left[\frac{3 \pi}{\mathrm{w}_{\mathrm{x}}}+\frac{6 \mathrm{w}_{\mathrm{y}}^{4}}{\left(\mathrm{w}_{\mathrm{x}}^{2}-1\right)\left(4 \mathrm{w}_{\mathrm{y}}^{2}-1\right)}\right. \\
& \sin \left(2 \psi_{0}\right)+\frac{2}{3} \sin \left(2 \psi_{1}\right)-\frac{2}{\mathrm{w}_{\mathrm{y}}} \sin \left(2 \pi \frac{\mathrm{w}_{\mathrm{y}}}{\mathrm{w}_{\mathrm{x}}}\right)+\frac{1}{4 \mathrm{w}_{\mathrm{y}}} \sin \left(4 \pi \frac{\mathrm{w}_{\mathrm{y}}}{\mathrm{w}_{\mathrm{x}}}\right)-\frac{2}{\mathrm{w}_{\mathrm{x}}^{2}-1}\left(\sin \left(2 \psi_{1}\right)\right. \\
& \left.\cos \left(2 \pi \frac{\mathrm{w}_{\mathrm{y}}}{\mathrm{w}_{\mathrm{x}}}\right)+\mathrm{w}_{\mathrm{y}} \cos \left(2 \psi_{1}\right) \sin \left(2 \pi \frac{\mathrm{w}_{\mathrm{y}}}{\mathrm{w}_{\mathrm{x}}}\right)\right)-\frac{1}{2\left(4 \mathrm{w}_{\mathrm{y}}^{2}-1\right)}\left(\sin \left(2 \psi_{1}\right) \cos \left(4 \pi \frac{\mathrm{w}_{\mathrm{y}}}{\mathrm{w}_{\mathrm{x}}}\right)\right. \\
& \left.\left.+2 \mathrm{w}_{\mathrm{y}} \cos \left(2 \psi_{1}\right) \sin \left(4 \pi \frac{\mathrm{w}_{\mathrm{y}}}{\mathrm{w}_{\mathrm{x}}}\right)\right]\right] \\
& \frac{\mathrm{D}_{21}}{\mathrm{~d}}=\frac{\mathrm{C}_{12}}{\mathrm{~d}}-\frac{1}{8 \mathrm{w}_{\mathrm{y}}^{2} \sin ^{4}\left(\psi_{0}\right)}\left[\left(1-\cos \left(2 \pi \frac{\mathrm{w}_{\mathrm{y}}}{\mathrm{w}_{\mathrm{x}}}\right)\right) \sin \left(2 \psi_{1}\right)+\mathrm{w}_{\mathrm{y}}\left(1-\cos \left(2 \psi_{1}\right)\right)\right. \\
& \left.\sin 2 \pi \frac{\mathrm{w}_{\mathrm{y}}}{\mathrm{w}_{\mathrm{x}}}\right]
\end{aligned}
$$


The spherical aberration coefficients $\mathrm{C}_{30} / \mathrm{d}$ and $\mathrm{C}_{12} / \mathrm{d}$ in convergence plane and $\mathrm{D}_{03} / \mathrm{d}$ and $\mathrm{D}_{21} / \mathrm{d}$ in divergence plane are determined and the results are shown in Figs. (5) to (8) as a function of the gap angle $2 \Gamma$. From Fig. (5) the coefficient $\mathrm{C}_{30} / \mathrm{d}$ is always negative and it has a minimum value $\mathrm{C}_{30} / \mathrm{d}=-1.303$ at $2 \Gamma=45.55^{\circ}$. Furthermore, the coefficients $\mathrm{C}_{12} / \mathrm{d}, \mathrm{D}_{03} / \mathrm{d}$, and $\mathrm{D}_{21} / \mathrm{d}$ may be either positive or negative due to the non-rotationally symmetric field of quadrupole lenses. As the gap angle $2 \Gamma$ increases, the aberration coefficients $\mathrm{C}_{12} / \mathrm{d}, \mathrm{D}_{03} / \mathrm{d}$ and $\mathrm{D}_{21} / \mathrm{d}$ decrease as shown clear in Figs. (6) to (8). However, when the gap angle $2 \Gamma=45.55^{\circ}$ the coefficient $\mathrm{D}_{03} / \mathrm{d}$ approaches to the maximum value at 0.123 . The lowest absolute values of spherical aberration coefficients $\mathrm{C}_{12} / \mathrm{d}$ and $D_{21} / d$ are accrue at range $45.5^{\circ} \leq 2 \Gamma \leq 46.00^{\circ}$ and the value of $D_{03} / d$ approaches to zero at $2 \Gamma=46.15^{\circ}$. The relative spherical aberration coefficients $\mathrm{C}_{12} / \mathrm{d}$ and $\mathrm{D}_{21} / \mathrm{d}$ are numerically greater than that of the coefficients $\mathrm{C}_{30} / \mathrm{d}$ and $\mathrm{D}_{03} / \mathrm{d}$.

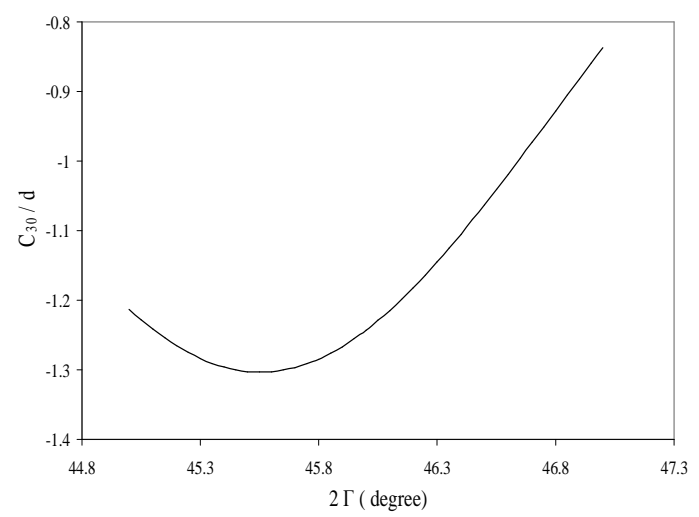

Fig.(5): The relative spherical aberration coefficient $C_{03} /$ d of electrostatic quadrupole lens of cylindrical concave electrodes as a function of gap angle $2 \Gamma$.

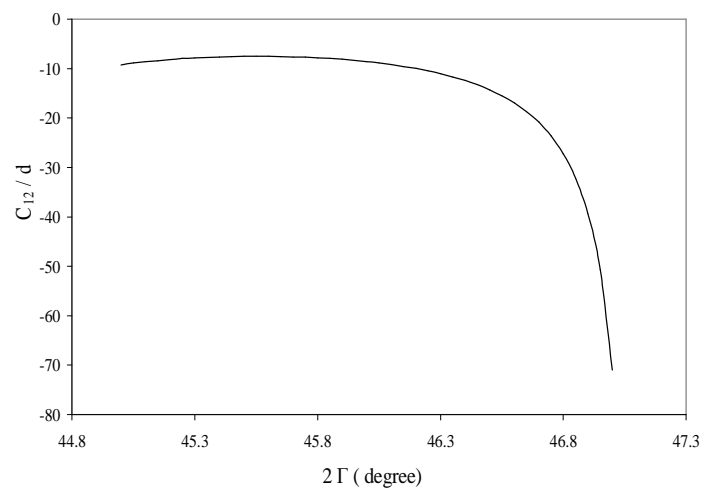

Fig.(6): The relative spherical aberration coefficient $C_{12} / d$ of electrostatic quadrupole lens of cylindrical concave electrodes as a function of gape angle $2 \Gamma$ in degree .

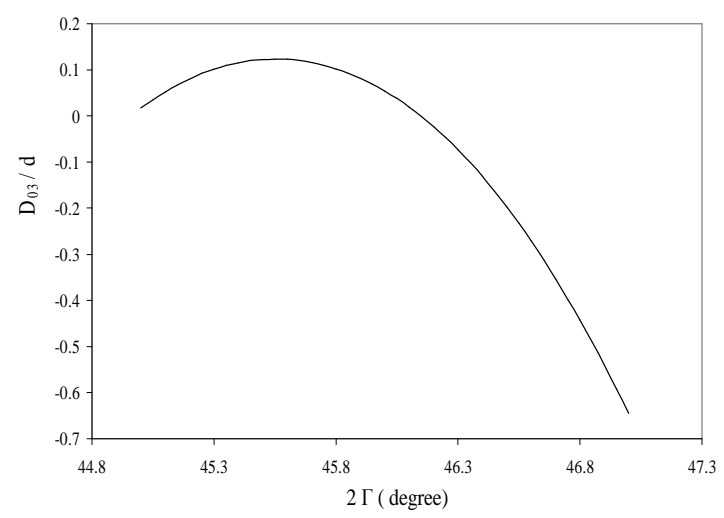

Fig.(7): The relative spherical aberration coefficient $D_{03} / d$ of electrostatic quadrupole lens of cylindrical concave electrodes as a function of gap angle $2 \Gamma$.

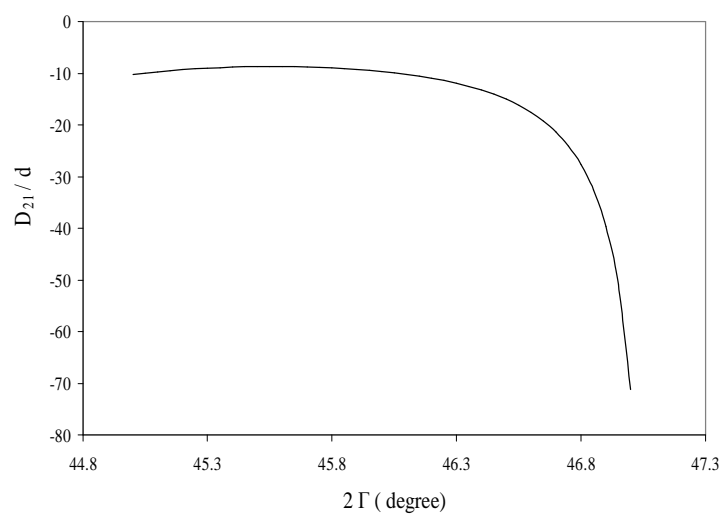

Fig.(8): The relative spherical aberration coefficient $D_{21} /$ d of electrostatic quadrupole lens of cylindrical concave electrodes as a function of gap angle $2 \Gamma$. 
Oday A. Hussein

\section{Chromatic Aberration}

The coefficients of chromatic aberration are given by [6]:

$$
\begin{aligned}
& \frac{\mathrm{C}_{\mathrm{cx}}}{\mathrm{d}}=-\frac{\mathrm{n}-1}{8} \frac{\beta^{2} \mathrm{~d}^{2}}{\sin \left(\pi \mathrm{w}_{\mathrm{x}}\right)^{2}}\left[\left(\frac{\sin \left(2 \pi \mathrm{w}_{\mathrm{x}}\right)}{\mathrm{w}_{\mathrm{x}}}-2 \pi\right)\left(\mathrm{m}_{\mathrm{x}}^{2}+1\right)+4 \mathrm{~m}_{\mathrm{x}}\right. \\
& \left(\frac{\sin \left(\pi w_{x}\right)}{w_{x}}-\pi \cos \left(\pi w_{x}\right)\right] \\
& \frac{\mathrm{C}_{\mathrm{cy}}}{\mathrm{d}}=\frac{\mathrm{n}-1}{8} \frac{\beta^{2} \mathrm{~d}^{2}}{\sin \left(\pi \mathrm{w}_{\mathrm{y}}\right)^{2}}\left[\left(\frac{\sin \left(2 \pi \mathrm{w}_{\mathrm{y}}\right)}{\mathrm{w}_{\mathrm{y}}}-2 \pi\right)\left(\mathrm{m}_{\mathrm{y}}^{2}+1\right)+4 \mathrm{~m}_{\mathrm{y}}\right. \\
& \left.\left(\frac{\sin \left(\pi w_{y}\right)}{w_{x}}-\pi \cos \left(\pi w_{y}\right)\right)\right] \\
& \mathrm{C}_{\mathrm{mx}}=\frac{\mathrm{n}-1}{8} \frac{\beta^{2} \mathrm{~d}^{2} \mathrm{f}_{\mathrm{x}}}{\mathrm{w}_{\mathrm{x}}^{2} \mathrm{~d}}\left[\left(\frac{\sin \left(2 \pi \mathrm{w}_{\mathrm{x}}\right)}{\mathrm{w}_{\mathrm{x}}}-2 \pi\right) \mathrm{m}_{\mathrm{x}}+2\left(\frac{\sin \left(\pi \mathrm{w}_{\mathrm{x}}\right)}{\mathrm{w}_{\mathrm{y}}}-\pi \cos \left(\pi \mathrm{w}_{\mathrm{x}}\right)\right)\right] \\
& C_{m y}=\frac{n-1}{8} \frac{\beta^{2} d^{2} f_{y}}{w_{y}^{2} d}\left[\left(\frac{\sin \left(2 \pi w_{y}\right)}{w_{y}}-2 \pi\right) m_{y}+2\left(\frac{\sin \left(\pi w_{y}\right)}{w_{y}}-\pi \cos \left(\pi w_{y}\right)\right)\right]
\end{aligned}
$$

where $\mathrm{u}$ is the object distance, $\mathrm{M}$ is the magnification and is given by:

$$
\begin{aligned}
\mathrm{M}_{\mathrm{x}} & =\frac{1}{\frac{\mathrm{dW}_{\mathrm{x}} \sin (\psi) \sin \left(\mathrm{W}_{\mathrm{x}} \psi\right)+\mathrm{d} \cos (\psi) \cos \left(\mathrm{W}_{\mathrm{x}} \psi\right)}{\sin ^{2}(\psi)\left[1+\left(\mathrm{z}-\mathrm{z}_{\mathrm{L}} / \mathrm{d}\right)^{2}\right] \mathrm{d}} \mathrm{u}+\frac{\mathrm{d} \cos \left(\mathrm{W}_{\mathrm{x}} \psi\right)}{\sin (\psi)}} \\
\mathrm{M}_{\mathrm{y}}= & \frac{1}{\frac{\mathrm{dWy} \sin (\psi) \sin (\mathrm{W} y)+\mathrm{d} \cos (\psi) \cos (\mathrm{Wy} \psi)}{\sin ^{2}(\psi)\left[1+\left(\mathrm{z}-\mathrm{z}_{\mathrm{L}} / \mathrm{d}\right)^{2}\right] \mathrm{d}} \mathrm{u}+\frac{\mathrm{d} \cos (\mathrm{Wy} \psi)}{\sin (\psi)}}
\end{aligned}
$$

The Figs. (9) to (12) show the effect of variation of the gap angle $2 \Gamma$ on chromatic aberration coefficients $\mathrm{C}_{\mathrm{cx}} / \mathrm{d}$ and $\mathrm{C}_{\mathrm{mx}}$ in convergence plane, and $\mathrm{C}_{\mathrm{cy}} / \mathrm{d}$ and $\mathrm{C}_{\mathrm{my}}$ in divergence plane. From Fig.(9), the coefficient $\mathrm{C}_{\mathrm{cx}} / \mathrm{d}$ is always negative and it's absolute value increases with increasing of $2 \Gamma$. The lowest absolute value of $\mathrm{C}_{\mathrm{cx}} / \mathrm{d}$ is accrue at wide range $45.5^{\circ} \leq 2 \Gamma \leq 46.00^{\circ}$. From Fig.(10) the coefficient $\mathrm{C}_{\mathrm{cy}} / \mathrm{d}$ is always positive and increases with increasing of $2 \Gamma$.

The lowest value of $\mathrm{C}_{\mathrm{cy}} / \mathrm{d}$ is accrue at wide range $45.5^{\circ} \leq 2 \Gamma \leq 46.00^{\circ}$. The value of $\mathrm{C}_{\mathrm{mx}} / \mathrm{d}$ and $\mathrm{C}_{\mathrm{my}} / \mathrm{d}$ is always positive and the behavior of $\mathrm{C}_{\mathrm{mx}} / \mathrm{d}$ is exactly opposite that of $\mathrm{C}_{\mathrm{my}} / \mathrm{d}$. At $2 \Gamma=45.55^{\circ}$, the value of
$\mathrm{C}_{\mathrm{mx}} / \mathrm{d}$ is maximum and equal to 0.813 where as $C_{m y} / d$ is minimum at 0.757 .

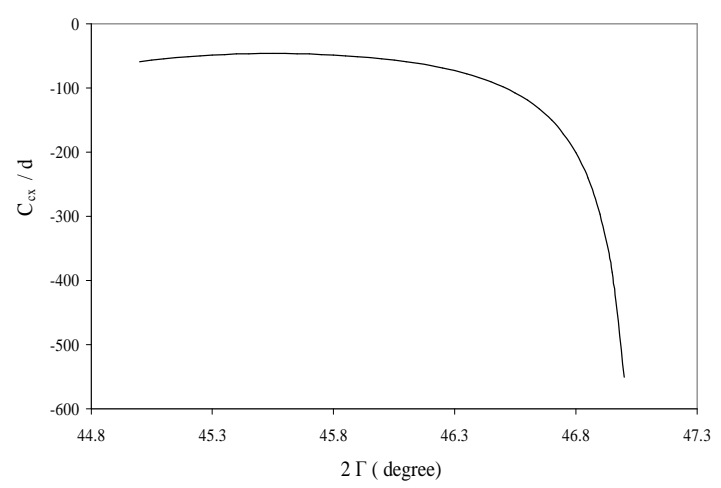

Fig.(9) : The relative chromatic aberration coefficient $C_{c x} / d$ of electrostatic quadrupole

lens of cylindrical concave electrodes as a function of gap angle $2 \Gamma$. 


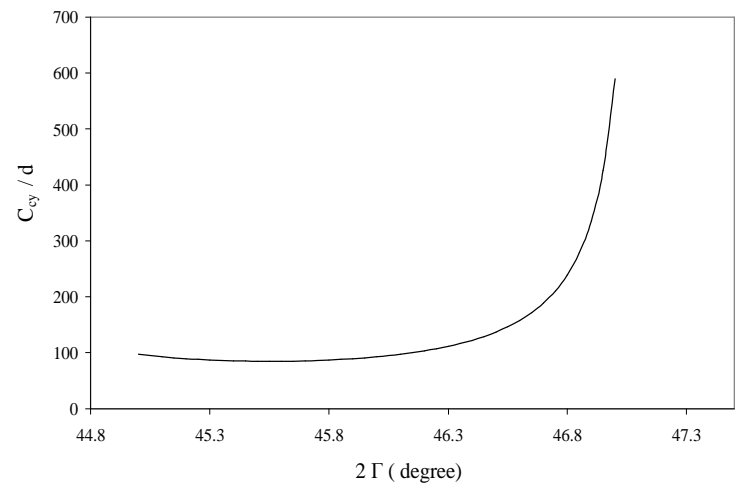

Fig.(10): The relative chromatic aberration coefficient $C_{c y} / d$ of electrostatic quadrupole lens of cylindrical concave electrodes as a function of gap angle $2 \Gamma$.

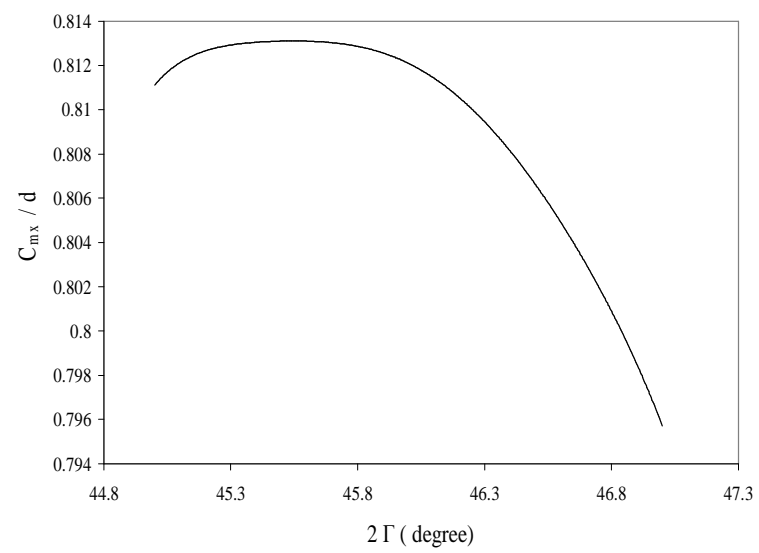

Fig.(11): The relative chromatic aberration coefficient $\mathrm{C}_{\mathrm{mx}}$ / d of electrostatic quadrupole lens of cylindrical concave electrodes as a function of gap angle $2 \Gamma$.

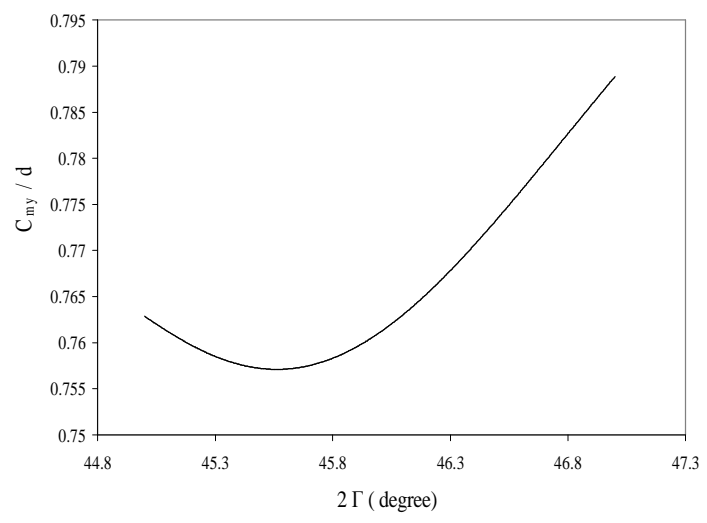

Fig.(12): The relative chromatic aberration coefficient $C_{m y} / d$ of electrostatic quadrupole lens of cylindrical concave electrodes as a function of gap angle $2 \Gamma$.

\section{Conclusions}

The quadrupole lens system has many variable geometrical and operational parameters; thus conclusive result is rather difficult. However, from the present investigation one may conclude the following:

(a) For cylindrical concave electrostatic quadrupole lens, the modified bell-shaped model gives good optical properties.

(b) The results of the calculations of the chromatic aberration coefficients show that the behavior of this coefficients in divergence plane is inverse to that at the convergence plane, therefore one can reduced only of them at the same time.

\section{References}

[1] M. Szilagyi, (1988), Electron and ion optics, (Plenum Press, New York).

[2] A. Kiss and E. Koltay, (1970), Investigations on the effective length of asymmetrized quadrupole lenses, Nucl. Instrum. Meth.78, 238-244.

[3] T. Hayashi and N. Sakudo, (1968), Quadrupole field in circular concave electrodes, Rev. Sci. Instrum., 39 (7), 958-961.

[4] L. P. Ovsyannikova and S. Ya. Yavor, (1969), Third-order of asymmetrized quadrupole lenses, Nucl. Instrum. Meth., 74, 185-190.

[5] S. Okayama and H. Kawakatsu, (1978), Potential distribution and focal properties of electrostatic quadrupole lenses, J. Phys. E: Sci. Instrum., 11, 211-216.

[6] P.W. Hawkes, (1970), Quadrupoles in electron lens design, Adv. Electronics and Electron Phys., Supplement 7, ed. L. Marton, (Academic Press, New York and London).

[7] A. D. Dymnikov, T. Ya. Fishkova and S. Ya. Yavor, (1965), Spherical aberration of compound quadrupole lenses and systems, Nucl. Instrum. Meth., 37, 268-275.

[8] P. Grivet, (1972), Electron Optics, (Pergamon Press, Oxford and New York)

[9] J. D. Larson, (1981), Electrostatic ion optics and beam transport for ion implantation, Nucl. Instrum. Meth., 189, 71-91. 
[10] S. Okayama, (1989), SPIE, Electronbeam, X-ray, and Ion-beam Technology: Submicrometer Lithographies VIII, 1089, pp 74-83

[11] T. Ya. Fishkova, L. A. Baranova and S. Ya. Yavor, (1968), Spherical aberration of stigmatic doublet of quadrupole lenses (rectangular model ), Sov. Phys. Tech. Phys., 13 (4), 520-525.

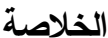

تم حساب التصميم الأمثل لعدسة كهروسكونية رباعية

ذات أقطاب اسطو انية مقعرة باستخدام طريقة المصفوفات المنات

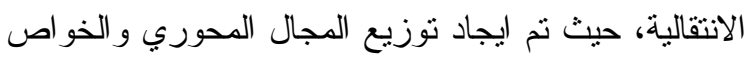

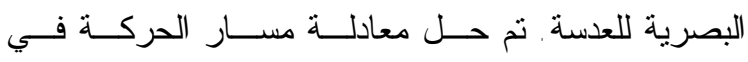

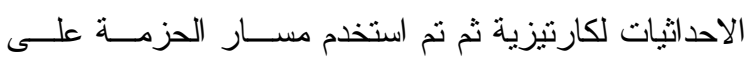

امتداد محور العدسة لحساب الخو اص البصرية للعدسة.

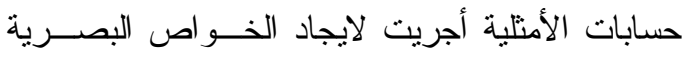

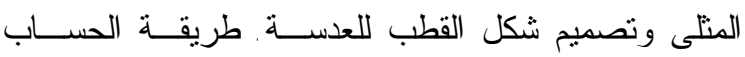

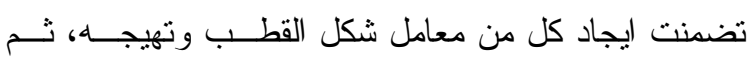

حساب معاملات الزيوغ في المستويين الافقي و العـامودي معادي

على امتداد المحور البصري.

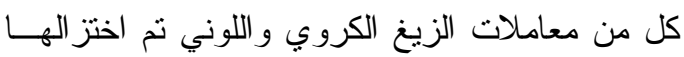

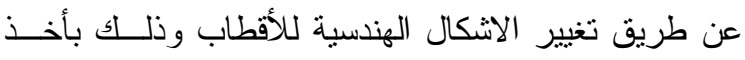

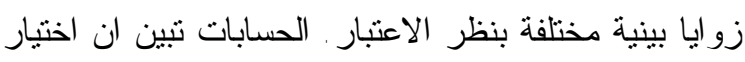

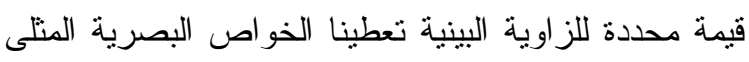

و القيمة الافضل لمعاملات الزيغ. 